ASIM-Mitteilungen AM 143

ARGESIM Report AR 40

\title{
SOMMERTREFFEN
}

VERKEHRSSIMULATION

2. August 2012

Universität zu Köln, Institut für Informatik

ISBN ebook 978-3-901608-79-7

DOI 10.11128/arep.40

ISBN print 978-3-901608-38-4

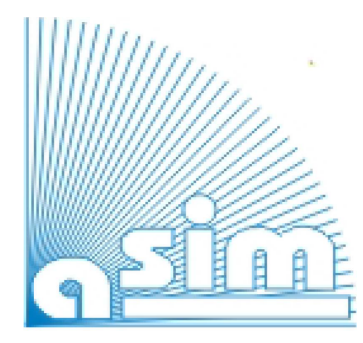





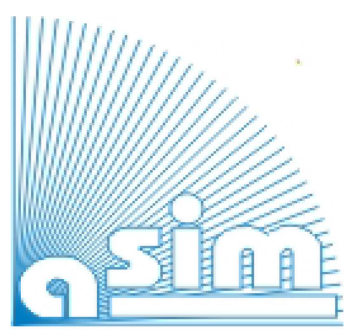

Fran ARGESIM 


\section{ARGESIM Reports}

Published by ARGESIM and ASIM, Arbeitsgemeinschaft Simulation, Fachausschuss 4.5 der GI

\section{Series Editor:}

Felix Breitenecker (ARGESIM / ASIM)

Div. Simulation, Vienna University of Technology

Wiedner Hauptstrasse 8 - 10, A - 1040 Vienna

Tel: +43-1-58801-11452, Fax: +43-1-58801-11499

Email: Felix.Breitenecker@tuwien.ac.at

\section{ARGESIM Report 40}

\section{ASIM - Mitteilungen AM 143}

Titel: Sommertreffen Verkehrssimulation 2012

Herausgeber: Oliver Ullrich

Daniel Lückerath

Email: daniel.lueckerath@iais.fraunhofer.de

ISBN ebook: 978-3-901608-79-7, 2021

DOI: 10.11128/arep.40

ISBN print 978-3-901608-38-4, 2012

Das Werk ist urheberrechtlich geschützt. Die dadurch begründeten Rechte, insbesondere die der Übersetzung, des Nachdrucks, der Entnahme von Abbildungen, der Funksendung, der Wiedergabe auf photomechanischem oder ähnlichem Weg und der Speicherung in Datenverarbeitungsanlagen bleiben, auch bei nur auszugsweiser Verwertung, vorbehalten.

(C) by ARGESIM / ASIM, Wien, 2012 - Universität zu Köln

ARGE Simulation News (ARGESIM)

c/o F. Breitenecker, Div. Simulation, Vienna Univ. of Technology

Wiedner Hauptstrasse 8-10, A-1040 Vienna, Austria

Tel.: +43-1-58801-11452, Fax: +43-1-58801-42098

Email: info@argesim.org; WWW: http://www.argesim.org 
Am 2. August 2012 fand in Köln zum ersten Mal die Workshop-Tagung „Sommertreffen Verkehrssimulation" statt. Das Sommertreffen soll jährlich stattfinden und insbesondere als Gelegenheit zum Erfahrungsaustausch für Doktoranden und andere Jungwissenschaftler dienen. Im Rahmen der Tagung können abgeschlossene Beiträge, in Arbeit befindliche Projekte sowie neue Werkzeuge, theoretische Überlegungen und Ideenskizzen vorgestellt und ohne fest vorgegebenen Zeitrahmen diskutiert werden. Wir freuen uns über Beiträge aus Bereichen wie Modellierung und Simulation von Öffentlichen und Individualverkehrssystemen, aber auch aus angrenzenden Gebieten wie Verkehrsoptimierung oder visualisierung. Auto- und Fahrradverkehr, Stadt- und Fernverkehrsbahnen, Schifffahrtsund Luftverkehr stehen gleichberechtigt nebeneinander.

Der Workshop begann mit einem Vortrag von Daniel Lückerath (Uni Köln) zum Thema „Thoughts on restauration of regular tram operation“, gefolgt von Sven Seele et al. (HS Bonn-Rhein-Sieg) mit dem Vortrag „Cognitive Agents with Psychological Personality for Traffic Simulations in Virtual Environments" und Thomas Dettmar et al. (ebenfalls HS Bonn-Rhein-Sieg) mit „Multi-Level Traffic Simulations for Virtual Environments“. Den Abschluss bildeten Sebastian Senge (TU Dortmund) mit dem Vortrag „Swarm Intelligence and Road Traffic Routing“ und Patrick Kuckertz (wieder Uni Köln) mit „Current work on the optimization of flight personnel schedules within project DOGS“".

Unser Dank gilt den Vortragenden und den anderen Teilnehmern, wir haben die angeregte Diskussion und die freundliche Atmosphäre als sehr angenehm empfunden. Weiterhin danken wir unserem Chef, Prof. Dr. Ewald Speckenmeyer, der uns die Möglichkeit gegeben hat den Workshop auszurichten. Darüber hinaus gilt unser Dank dem Sprecher der Fachgruppe „Grundlagen und Methoden in Modellierung und Simulation“ der Arbeitsgemeinschaft Simulation e.V. (ASIM), Prof. Dr. Thorsten Pawletta, der uns ermöglichte die Strukturen der ASIM zu nutzen.

Genügendes Interesse vorausgesetzt soll der Workshop im kommenden Jahr im Rahmen des alle zwei Jahre stattfindenden „Symposium Simulationstechnik“ der ASIM stattfinden.

Köln, im November 2012

Oliver Ullrich, Daniel Lückerath 
Sven Seele, Rainer Herpers, Christian Bauckhage, Peter Becker: Cognitive Agents with Psychological Personality for Traffic Simulations in Virtual Environments

Thomas Dettmar, Sven Seele, Rainer Herpers, Peter Becker: Multi-Level Traffic Simulations for Virtual Environments

Sebastian Senge: Swarm Intelligence and Road Traffic Routing

Nicht

Abgedruckt

Patrick Kuckertz: Current work on the optimization of flight personnel schedules within project DOGS 


\title{
Thoughts on restoration of regular tram operation
}

\author{
Daniel Lückerath \\ lueckerath@informatik.uni-koeln.de \\ Department of Computer Science, University of Cologne, \\ Institute of Communications Engineering, Cologne University of Applied Sciences
}

\section{Introduction}

Within the scope of our project "Computer Aided Traffic Scheduling" (CATS) we develop methods and applications to generate and evaluate robust time tables, which adhere to transport planning requirements. A detailed description of the project and its software modules can be found in $[5,6]$.

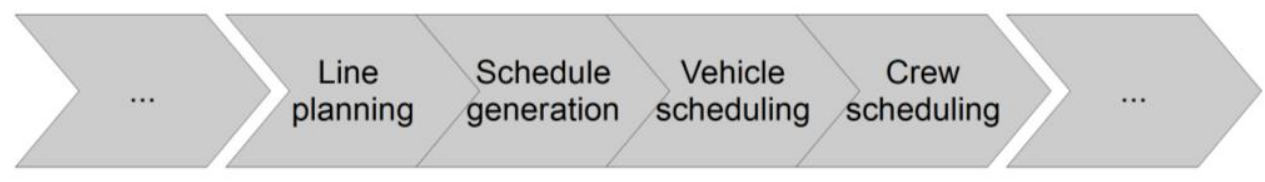

Figure 1: Shortened planning process of urban public transportation

The planning process of urban public transportation can be roughly divided into four different phases (see figure 1). Until now our research was focused on schedule generation with some necessary forays into the closely linked fields of line planning and vehicle scheduling. As described above, our research was until now concentrated on generating schedules which keep small delays at a local level, i.e. to minimize the impacts of delays on follow-up vehicles. Long lasting disturbances, whose impacts generally cannot be counteracted by schedule characteristics alone, were ignored until now. We now want to broaden the scope of our project and examine the applicability of rescheduling and re-routing measures during the daily operation of urban public transportation systems.

Rescheduling aims for the generation of transitional schedules in order to cope with the impacts of long lasting disturbances. Not only is the generation of those temporary schedules time-critical but the resulting time tables should also be robust and allow for reinstatement of the original schedule after the disturbance wore off/subsided.

\section{Literature review}

Research on rescheduling and re-routing is mainly applied to long distance transportation. Corman, D'Ariano, Pacciarelli and Pranzo in [1] develop a tabu search algorithm for re-routing trains during daily operation. In [2] they present a bi-objective optimization approach to minimize train delays as well as missed connections by dynamically switching the order of trains at common stations (therefore changing the underlying schedule).

Darmanin, Lim and Gan in [3] propose a new recovery strategy for Metro Train Melbourne, which employs existing bus lines for bypassing obstructed train tracks. 
A similar approach for urban public transportation is proposed by Zeng, Durach and Fang in [7]. They examine the circumstances under which it is profitable for a tram company to cooperate with taxi companies in order to transport stranded passengers to the next regularly served station.

Ginkel and Schöbel in [4] propose an optimization approach for the bi-criteria delay management problem in public transportation, which minimizes vehicle delay as well as missed connections. Other than Corman, D'Ariano, Pacciarelli and Pranzo in [2] Schöbel and Ginkel focus on bus-to-train-delay.

\section{Restoration of regular tram operation}

In order to narrow the huge research field of rescheduling and re-routing we initially want to focus on one traffic system only, without consideration of replacement vehicles or standby personnel. Thus we may adapt part of our existing methods and applications, e.g. as a first step to generate temporary schedules we could apply the genetic algorithm described in [6].

Alongside the adaption of our existing methods we will also conduct an applicationoriented comparison of existing rescheduling and re-routing strategies. In order to assess the applicability of these strategies we will develop a visualisation module that enables us to analyse the effects of small, incremental modifications to a schedule. Furthermore the existing optimization module should be modified in such a way that an existing schedule can be evaluated using the underlying objective function.

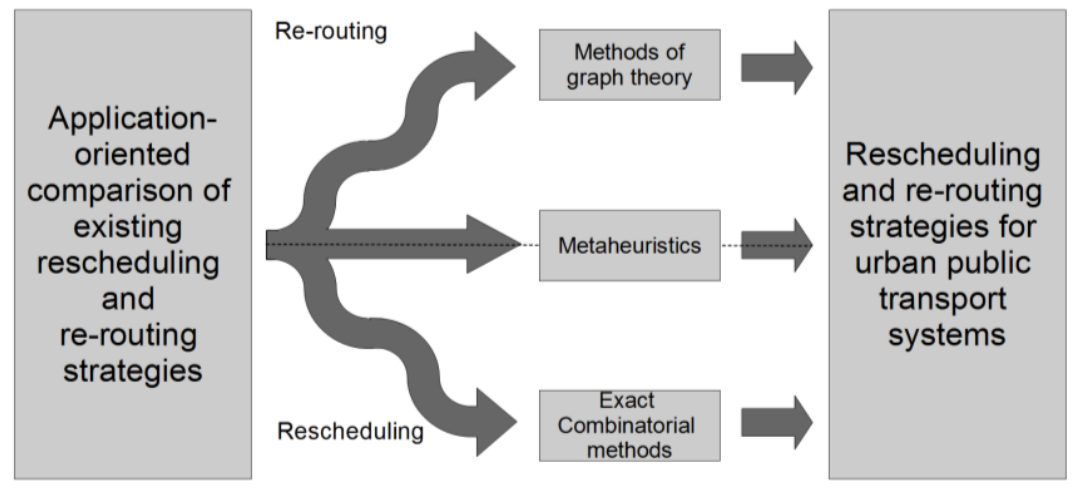

Figure 2: Road map to rescheduling and re-routing strategies for urban public transport systems

Independent of the results of the comparison we see at least three procedural paths (see figure 2): methods of graph theory (especially applicable for re-routing), metaheuristics like genetic algorithm, ant colony optimization or simulated annealing, and exact methods like branch and bound.

Based on the assessment of existing strategies and experiments using the aforementioned procedural paths, we will develop an (online-) optimization methodology and module to generate and evaluate special rescheduling and re-routing strategies for urban public transportation systems. 


\section{Pending questions/unresolved issues}

There are still numerous questions that have to be addressed until the desired optimization approach is finished.

First of all, which kinds of disturbances are severe enough to justify rescheduling or re-routing? Especially re-routing entails excessive changes to the schedule of different lines and therefore should only be applied after serious/profound disturbances. Additionally, a clear definition of re-routing measures has to be formulated, i.e. which measures are summarized under the term re-routing.

Because rescheduling and re-routing takes place during daily operations, any application generating rescheduling/re-routing strategies is time-critical. This has to be taken into account while developing rescheduling/re-routing strategies and applications.

At last we have to decide how the generated, potential solutions should be evaluated, i.e. which criteria should be considered. It seems obvious to consider robustness, but other criteria like adherence to transport planning requirements or the number of omitted stations seem also promising.

\section{Acknowledgements}

This work was supported by Rhein Energie Stiftung Jugend Beruf Wissenschaft under grant number W-10-2-002.

\section{References}

[1] Corman, F., D'Ariano, A., Pacciarelli, D., Pranzo, M.: A tabu search algorithm for rerouting trains during rail operations. Transportation Research Part B: Methodologial, 44 (2010), pp. 175-192.

[2] Corman, F., D'Ariano, A., Pacciarelli, D., Pranzo, M.: Bi-objective conflict detection and resolution in railway traffic management. Transportation Research Part C: Emerging Technologies, 20 (2012), pp. 79-94.

[3] Darmanin, T., Lim, C., Gan, H. S.: Public Railway Disruption Recovery Planning: A New Recovery Strategy for Metro Train Melbourne. Proceedings of the $11^{\text {th }}$ Asia Pacific Industrial Engineering and Management Systems Conference, 7 (2010).

[4] Ginkel, A., Schöbel, A.: To wait or not to wait? The bicriteria delay management problem in public transportation. Transportation Science, 41 (2007), pp. 527-538.

[5] Lückerath, D., Ullrich, O., Speckenmeyer, E.: Modeling time table based tram traffic. Simulation Notes Europe (SNE), 22 (2012).

[6] Ullrich, O., Lückerath, D., Franz, S., Speckenmeyer, E.: Simulation and optimization of Cologne's tram schedule. Simulation Notes Europe (SNE), 22 (2012).

[7] Zeng, A. Z., Durach, C. F., Fang, Y.: Collaboration decisions on disruption recovery service in urban public tram systems. Transportation Research Part E: Logistics and Transportation Review, 48 (2012), pp. 578-590. 


\title{
Cognitive Agents with Psychological Personality Profiles for Traffic Simulations in Virtual Environments
}

\author{
Sven Seele ${ }^{1}$, Rainer Herpers ${ }^{1,2,3}$, Christian Bauckhage ${ }^{4}$, Peter Becker ${ }^{1}$ \\ sven.seele@h-brs.de
}

\section{Introduction}

Traffic simulations are typically concerned with modeling human behavior as closely as possible to create realistic results. In conventional traffic simulations used for road planning or traffic jam prediction only the overall behavior of an entire system is of interest. In virtual environments, like digital games, simulated traffic participants are merely a backdrop to the player's experience and only need to be "sufficiently realistic". Additionally, restricted computational resources, typical for virtual environment applications, usually limit the complexity of simulated behavior in this field. More importantly, two integral aspects of real-world traffic are not considered in current traffic simulations from both fields: misbehavior and risk taking of traffic participants. However, for certain applications like the FIVIS bicycle simulator, these aspects are essential.

The FIVIS bicycle simulator is an immersive virtual reality application developed at the Bonn-Rhein-Sieg University of Applied Sciences [4,5]. One of its main intentions is to provide a safe environment for road safety training of children. For this, trainees need to be put into dangerous traffic situations that are created by incautious behavior and misbehavior of other traffic participants. Such situations are generally created using scripted events, which leads to trainees learning the sequences of the scripts at predetermined locations. Instead, they should learn how to recognize potentially dangerous situations and how to react to them.

To achieve this goal, the objective of the AVeSi project ("Agentenbasierte Verkehrssimulation mit psychologischen Persönlichkeitsprofilen" - engl.: "Agent-based Traffic Simulations with Psychological Personality Profiles") is to integrate a self-driven traffic simulation into the FIVIS simulator, which should be as realistic as possible. This requires traffic participants to misbehave and take risks, but only in situations where it makes sense to an observer. Therefore, it is proposed to model cognitive processes of real-world traffic participants to achieve such behavior. To provide individual behavior for each participant, these cognitive processes should be based on a psychological personality profile as suggested in previous work by Kutz et al. [6]. Here we present our concept for such virtual traffic agents and associated challenges as well as preliminary results.

\footnotetext{
${ }^{1}$ Bonn-Rhein-Sieg University of Applied Sciences, Department of Computer Science

${ }^{2}$ York University, Department of Computer Science and Engineering, Canada

${ }^{3}$ University of New Brunswick, Department of Computer Science, Canada

${ }^{4}$ Bonn-Aachen International Center for IT, University of Bonn
} 


\section{Modeling of Cognitive Traffic Agents}

To provide a realistic traffic simulation, simulated traffic agents need to behave sufficiently realistic. Besides following traffic rules, such behavior should be individual and include risk-taking, misbehavior and mistakes. Especially the latter is a defining characteristic of every-day traffic and an essential element of road safety education. Creating such traffic agents will be the final objective, but achieving it requires several problems to be solved on the way. We presume that the following aspects should make traffic simulations in virtual environments more realistic.

\subsection{Persistent Traffic Agents}

In traffic simulations for virtual environments, computational resources are typically saved by removing traffic agents once they leave the user's field of view. However, this can lead to inconsistencies in the virtual world and break the user's immersion. Thus, to make a simulation more realistic, virtual agents should be simulated throughout the entire virtual environment. At the same time, simulating all agents with the same amount of detail would be a waste of scarce computational resources or even impossible. The idea is to introduce a second simulation layer in which agents are simulated with less detail reducing computations. At the same time, agents could persist throughout the entire simulated system. The currently proposed idea involves an adaptation of queueing-based networks to realize persistent traffic agents. Details can be found in [3].

\subsection{Psychological Personality Profiles}

Real-world traffic participants all follow the same rules. However, everyone does so with slight but noticeable differences. Therefore, an additional aspect to achieve more realistic traffic agents is to provide individual behavior. This individual behavior should also be the foundation of risky and dangerous behavior. In [7] Kutz et al. presented a concept of more realistic traffic agents for virtual environments based on the "Five-Factor Model (FFM)" from psychology. The model suggests that a human's personality can be uniquely defined using five distinct character traits: openness, conscientiousness, extraversion, agreeableness, and neuroticism. Herzberg related driving behavior to three psychological prototypes (undercontrolled, overcontrolled, resilient) which are based on the character traits of the FFM [6]. Based on this research, we enhanced regular rulebased traffic agents with a psychological personality profile assigning them to one of the three prototypes. The enhanced agents were put into a scenario that cannot be handled by regular rule-based traffic agents. In this scenario, an uncontrolled four-way intersection with a priority-to-the-right system was modeled (see Figure 1). When four agents reach the intersection at about the same time, each has to yield to the one coming from the right creating a deadlock situation. In our experimental scene, such deadlocks occurred within less than a minute on average even for relatively small numbers of traffic agents (up to only $7 \%$ of maximum road capacity). The extended agents are able to detect deadlock situations using a simple model of visual perception. Once the deadlock is detected, one of the agents will give up its right of way based on its psychological prototype (cf. Figure 1). While this results in an agent actively breaking the priority-to-the-right rule, it resolves the situation and keeps traffic flowing. More detailed descriptions and results can be found in [8], which indicate how traffic simulations for virtual environments can 
benefit from even simple cognitive models. We are currently investigating a different scenario that aims at modeling risk-taking behavior of drivers having to maneuver around an obstacle (e.g. another vehicle that is double-parked) while facing opposing traffic. In this scenario a simple emotion model should be added to the traffic agents to be able to reproduce the effects of prolonged waiting times on the decisions made by members of the three psychological prototypes.

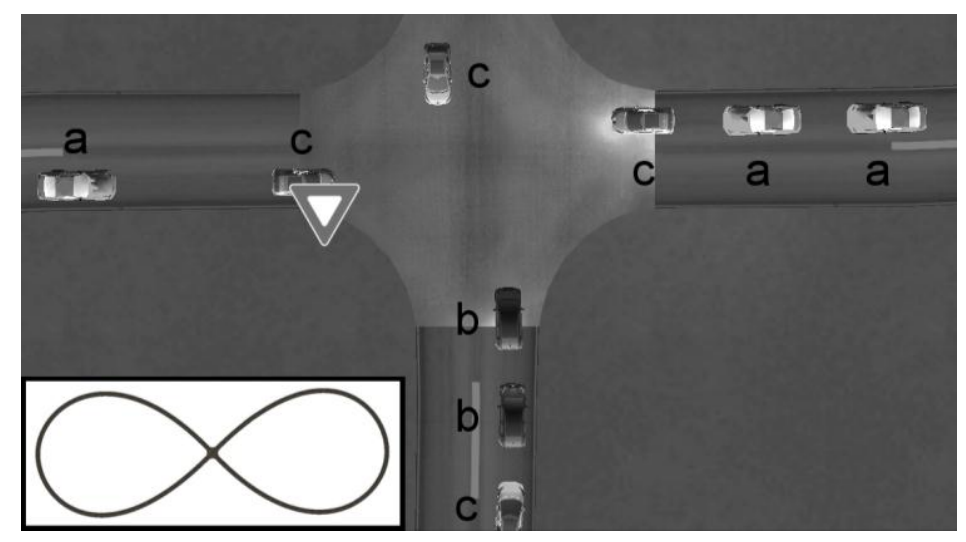

Figure 1: To evaluate agents with personality profiles, a closed road system with an uncontrolled four-way intersection was modeled as seen in the bottom left corner. Vehicle types represent psychological prototypes: undercontrolled (a), overcontrolled (b), and resilient (c). The scene depicts a resilient driver waiving its right of way (indicated by a yield sign) allowing the driver on its left to cross the intersection, which resolves the deadlock (image based on [8]).

\subsection{Road Network Representation}

To test our models, a suitable representation of the road network is required that enables traffic agents to query necessary semantic information about their environment. Such information includes the position of road signals, speed limits, road priorities and more. The OpenDrive standard was chosen as basis for this representation as it provides a detailed and established format for road descriptions, backed by major companies like Daimler and $\mathrm{BMW}^{5}$. Using a standardized representation as basis does not only allow incorporating third-party software, which uses the same standard, into our workflow, but also a simple and rapid adaption of our representation and scenarios for other applications. Currently, we are working on extending the OpenDrive description with components necessary to support possible cognitive processes including, for example, knowledge representation, learning, and anticipation. The finished road representation should then be used by the traffic agents to create symbolic representations of their knowledge about the road network. These symbols can then be used for reasoning and planning.

\footnotetext{
${ }^{5}$ www.opendrive.org
} 


\subsection{Machine Learning}

In an alternative approach, decision-making could be based on machine learning techniques instead of symbolic reasoning. Using such techniques, for example, neural networks, it was achieved to equip non-player characters in a first person shooter game with more human-like behavior concerning navigation and weapon selection (see [1] and [2]). The assumption is that a similar approach can be applied to the task of driving in virtual environments. Ideally, the finished system would be able to represent human-like behavior learned from users steering a vehicle within the virtual environment. To account for varying and individual behavior, the system could be extended by modules modeling human errors and links to the aforementioned psychological prototypes. Optionally, neural networks could be used as a supplementary approach to symbolic agents in the form of modules used for specialized behavior applicable in certain situations or necessary for specific tasks.

\section{Conclusions}

Modeling persistent traffic agents whose behavior is inspired by human cognitive processes and personalities should improve road safety training applications, since they reflect real world traffic conditions more realistically. We described our current concepts to possibly achieve this goal and mentioned promising results of an early implementation involving psychological prototypes based on the "Five-Factor Model". Future work will test the feasibility of the current approach in different and more complex traffic scenarios. With the concept of a road network representation for virtual environments, the foundation for cognitive traffic agents is currently being evaluated and developed. Finally, we discussed an alternative approach for modeling human driving behavior in virtual environments that utilizes machine learning techniques. Realizing the presented ideas would not only benefit the targeted FIVIS simulator, but also other driving/traffic simulators and in particular traffic simulations in digital games.

\section{Acknowledgments}

The FIVIS project was funded by the BMBF-FH3 Program "Angewandte Forschung an Hochschulen im Verbund mit der Wirtschaft", funding for the FIVIS 2 project was provided by the DGUV (FP 307), and the AVeSi project is being funded by the FHprofUnt Program of the BMBF (17028X11).

\section{References}

[1] Bauckhage, Christian, et al.: Learning Human-Like Opponent Behavior for Interactive Computer Games, In Pattern Recognition, Vol. 2781, Springer, 2003.

[2] Bauckhage, Christian, Thurau, Christian: Towards a Fair 'n Square Aimbot - Using Mixtures of Experts to Learn Context Aware Weapon Handling, In Proc. GAMEON, EUROSIS-EIT, 2004. 
[3] Dettmar, Thomas, Seele, Sven, Herpers, Rainer, Becker, Peter: Multi-Level Traffic Simulations for Virtual Environments, In Tagungsband ASIM Sommertreffen Verkehrssimulation, ARGESIM, 2012.

[4] Herpers, Rainer, et al.: Multimedia Sensory Cue Processing in the FIVIS Simulation Environment, In Multiple Sensorial Media Advances and Applications: New Developments in MulSeMedia, IGI Global, 2011.

[5] Herpers, Rainer, et al.: FIVIS - A Bicycle Simulation System, World Congress on Medical Physics and Biomedical Engineering (WC 2009), IFMBE Proceedings Vol. 25/4, Springer, 2009.

[6] Herzberg, Philipp Y., Beyond "accident-proneness": Using Five-Factor Model prototypes to predict driving behavior, In Journal of Research in Personality No. 6, Vol. 43, Elsevier, 2009.

[7] Kutz, Michael, Herpers, Rainer: Urban Traffic Simulation for Games, In Future Play '08 Proc. of the 2008 Conference on Future Play: Research, Play, Share, ACM, 2008.

[8] Seele, Sven, Herpers, Rainer, Bauckhage, Christian: Cognitive Agents for Microscopic Traffic Simulations in Virtual Environments. To appear in: Entertainment Computing - ICEC 2012, Springer, 2012. 


\title{
Multi-Level Traffic Simulations for Virtual Environments
}

\author{
Thomas Dettmar $^{1}$, Sven Seele ${ }^{6}$, Rainer Herpers ${ }^{1,7,8}$, Peter Becker ${ }^{1}$ \\ Thomas.Dettmar@inf.h-brs.de
}

\section{Introduction}

Traditionally traffic simulations are used to predict traffic jams, plan new roads or highways, and estimate road safety. They are also used in computer games and virtual environments. There are two general concepts of modeling traffic: macroscopic and microscopic modeling. Macroscopic traffic models take vehicle collectives into account and do not consider individual vehicles. Parameters like average velocity and density are used to model the flow of traffic. In contrast, microscopic traffic models consider each vehicle individually. Therefore, vehicle specific parameters are of importance, e.g. current velocity, desired velocity, velocity difference to the lead vehicle, individual time gap.

Traffic simulations in virtual environments utilize microscopic approaches, but often lack persistence. To save computational resources, usually only the surroundings of the user are simulated. Agents that leave the vicinity of the user are simply removed from the simulation. This can lead to situations in which the user follows a traffic agent around a corner to find the agent gone. The FIVIS simulator features a virtual environment representing real cities which can be explored by bicycle (see [6,7]). This system is used as road safety education application for school children. In its current development state there is no dynamic self-driven traffic simulation integrated into FIVIS. All agents simply follow a predefined route and are only able to accelerate and decelerate along the way. Integrating a self-driven traffic simulation into FIVIS is the objective of the AVeSi ("Agentenbasierte Verkehrssimulation mit psychologischen Persönlichkeitsprofilen" Engl. "Agent-based traffic simulation with psychological personality profiles") project. The project consists of two parts both aiming at improving the realism of common traffic simulations. One part of this project is to develop cognitive agents for more realistic agent behavior (see [10]). The other part, presented here, is to create persistent agents.

In this case, persistence means that an agent is not deleted after leaving the users vicinity but is continuously simulated. The easiest way to create persistent traffic agents would be to define the vicinity as large as the environment. As already mentioned due to limited computational resources this cannot be done. The currently implemented traffic simulation for FIVIS, for example, already uses up to $60 \%$ of the CPU while only 20 vehicles are being simulated. To be able to realistically simulate traffic at least 1000 vehicles should be simulated. The objective of this contribution is to develop a second simulation level which simulates traffic agents outside the user's vicinity. This is to be achieved by transferring the agent to a coarser level of the simulation where the agent is simulated with less detail. If the agent re-enters the user's vicinity, it is transferred back to the original level of the simulation.

\footnotetext{
${ }^{6}$ Bonn-Rhein-Sieg University of Applied Sciences

${ }^{7}$ York University, Canada

${ }^{8}$ University of New Brunswick, Canada
} 


\section{Initial Approach}

The AVeSi project uses the Intelligent-Driver-Model (IDM) (see [13]) for simulating the microscopic vicinity of the user. In a first approach the idea was to link this microscopic traffic simulation with a macroscopic traffic simulation where the second simulation level is modeled. To establish the link, a particle system was supposed to be used as basis for the macroscopic simulation as proposed in [10]. The most important characteristic for successfully linking these models is the traffic flow, which describes how many vehicles pass a road section in a particular time step (see [13]). The existence of same or similar characteristics is crucial to transfer vehicles from one simulation level to the other. As a macroscopic model the Lighthill-Whitham-Richards-Model (LWR) was chosen because it requires a minimum set of parameters (see [13]).

\subsection{Applying a Traffic Model}

Within the LWR model all vehicles are treated equally, meaning it is not distinguished between different vehicle types. All simulated vehicles have the same attributes and attribute values. Most commonly the simulated road is divided into sections. Each section is described by its current density $\rho$ and the maximum density $\rho_{\max }$. The sections are separated from each other by road elements that might influence the density, like traffic lights or intersections. For each section the velocity $\mathrm{v}$, which is valid for all cars within the section, is calculated based on the following equation:

$$
v=v_{\max } *\left(1-\frac{\rho}{\rho_{\max }}\right),
$$

with $v_{\max }$ being the maximum allowed velocity. A thorough motivation of the equation can be found in [13].

In difference to the LWR, the IDM does not calculate a velocity that is valid for all vehicles. The IDM calculates the acceleration for each and every vehicle that allows the vehicle to reach its desired velocity. Here two cases have to be differentiated. In the first case - the free flow mode - the desired velocity is predefined. In the second case - the car following mode - the desired velocity is given by the velocity of and distance to the vehicle in front. This is achieved by the following equation:

$$
\dot{v}=a\left[1-\left(\frac{v}{v_{0}}\right)^{\delta}-\left(\frac{s^{*}(v, \Delta v)}{s}\right)^{2}\right] \text { with: } s^{*}(v, \Delta v)=s_{0}+\max \left(0, v T+\frac{v, \Delta v}{\sqrt[2]{a b}}\right)
$$

where $\mathrm{a}$ is the driver's desired acceleration, $\mathrm{v}$ the current velocity, $\mathrm{v}_{0}$ the desired velocity, $\mathrm{s}$ the current headway, $\mathrm{s}^{*}$ the desired headway, $\mathrm{s}_{0}$ the minimum headway, $\mathrm{T}$ the time gap to the lead vehicle, $\Delta v$ the velocity difference between the vehicle and its leader, and $\mathrm{b}$ the desired deceleration. Again a thorough motivation of the equation and a list of standard parameter values can be found in [13]. 
These two traffic models have been adapted to a particle system. Usually particles in a particle system are moved by physical laws, like Newton's law. If Newton's law would be applied to the particles, their new positions would be calculated, e.g. by gravity and wind. In the case presented here, a particle represents a vehicle. Therefore the new position of a particle needs to be calculated by acceleration and velocity and not by gravity and wind. Depending on the traffic model in use, either a new velocity (LWR) or a new acceleration (IDM) is calculated and applied to the particles. Since the LWR does not consider acceleration, this term can be neglected or set to zero, and only the velocity term is used. For the IDM, both terms are used to calculate the position of a vehicle.

\subsection{Set-up of Experiments}

The scenario used for evaluation purposes was a single highway lane with a length of two kilometers. In this set-up there were no entrance or exit ramps. New vehicles entered the road section randomly between one and three seconds at their desired velocity. Within the experiments three different types of vehicles were analyzed, each with a particular desired velocity (cars $=120 \mathrm{~km} / \mathrm{h}$, small trucks $=100 \mathrm{~km} / \mathrm{h}$, and buses $=80 \mathrm{~km} / \mathrm{h}$ ). The maximum density was 160 vehicles per kilometer, assuming an average vehicle length of about 5.5 meters and an average gap of 70 centimeters at maximum density (see [1]). One objective was to implement a macroscopic traffic simulation that meets the required characteristics - in this case the same traffic flow - of a microscopic traffic simulation. To compare these models the traffic flow was measured for each simulated section. Traffic flow is defined as the product of velocity and density (see [1,13]), e.g. the traffic flow $f$ for the LWR is given by:

$$
f=v_{\max } *\left(1-\frac{\rho}{\rho_{\max }}\right) * \rho
$$

\subsection{Results of the Initial Approach}

Figure 1 shows the results of the simulations. While the adaption of the two traffic models to the particle system was successful, the observed traffic flows did not show the desired similarity. The figure shows that there is a significant difference with regard to this criterion, which makes this approach infeasible for the creation of persistent traffic agents. 


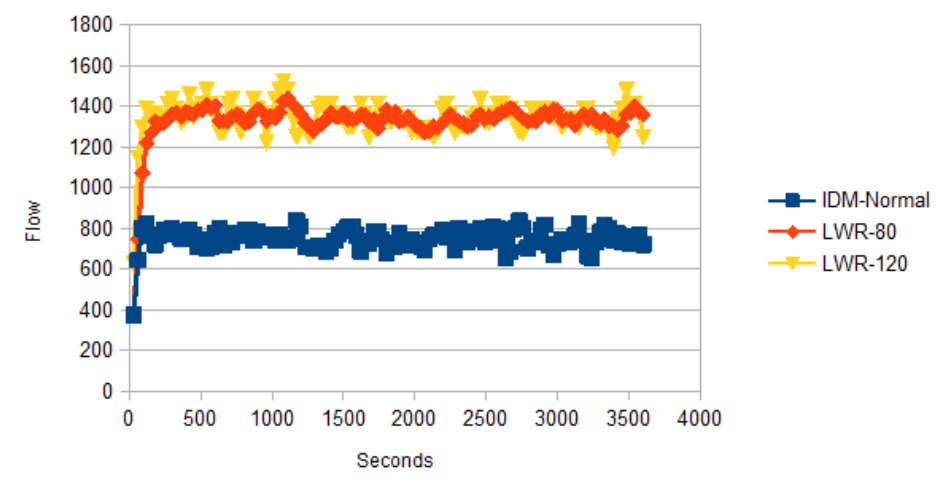

Figure 2: Comparison of the traffic flow of the basic LWR simulation to the traffic flow of the IDM simulation. The two LWR simulations - one for the desired velocity of $80 \mathrm{~km} / \mathrm{h}$ and one for $120 \mathrm{~km} / \mathrm{h}$ - show little difference while the traffic of the IDM is only half as high compared to the LWR

Modifications to either model did not show improved results. Perhaps a second order macroscopic traffic model, like the Gaskinetic-Based-Traffic-Model [12,13], could be used to produce better results. However, besides this approach, a number of other strategies to improve realism within traffic simulations exist. Models which appear to achieve results more efficiently are so called queuing models. Thus, the approach of using a queuing-based model is motivated in the next section.

\section{Queuing-based Traffic Model}

This approach follows a different strategy and is still in development. Here the less detailed simulation level will be based on the queuing model FASTLANE developed by Christian Gawron [3,4]. Compared to the previously discussed macroscopic traffic model, queuing models can be classified as microscopic models. Here every vehicle is considered as an individual and not as part of a collective as in a macroscopic model. Compared to a microscopic traffic model like the IDM, vehicles are modeled with less detail, e.g. the exact position on the road is not of interest. Further, queuing models are very fast and can handle a large amount of traffic participants. The FASTLANE queuing model has already been used in $[2,5,11]$ to simulate large, densely populated, areas. Within queuing models the road network, which is to be simulated, is represented by a graph. Edges represent roads and vertices represent signalized or unsignalized intersections. In Gawrons model edges have the following parameters: capacity $\mathrm{C}$ (the amount of vehicles which can leave the road in one time step), the length of the road L, the number of lanes $n_{\text {lanes }}$ on the road, the free flow velocity $v_{0}$, and the maximum density $\rho_{\max }$ (the maximum number of vehicles on the road at the same time). By limiting the number of vehicles on the road, this approach is able to model spill-backs. A spillback occurs when the adjacent road or intersection is full and therefore unable to provide space for further vehicles. When a vehicle enters a road, a duration time is calculated for 
it. After this time, the vehicle has reached the end of the road and is transferred to an intersection. For calculating the duration time three cases have to be considered. If the capacity is higher than the demand (amount of vehicles on the road), all vehicles can travel at the free flow velocity or at their own maximum velocity. If the capacity is lower than the demand, a queue forms which has to be taken into account when calculating the duration time. In this case the duration time is slightly higher than in the former case. In the third case, the following intersection or road is full, meaning no vehicle can enter this road or intersection, resulting in a traffic jam. Here the duration time can be indefinite.

In order to apply this model to the AVeSi project the following problems need to be solved: As mentioned above, the exact position is not needed and therefore not part of the FASTLANE model. However, for this project it is highly important to know the exact vehicle positions in order to initiate the vehicle transfer between the two simulation levels. Therefore, questions that need to be answered are: How can the vehicle be located on the road in order to be transferred? When does the transfer take place? How are the intersections modeled? These issues are currently being investigated.

\section{Conclusions}

Creating persistent traffic agents should improve realism within traffic simulations in virtual environments. The first approach presented here is not suited for this task due to the strong difference of the traffic flow of the two traffic models used. Also, modifications to the LWR did not achieve better results. Therefore, an alternative approach is needed. The queueing model FASTLANE was selected since it is also a microscopic model and therefore no transition link, like a particle system, is necessary. Further, the FASTLANE model can be used to simulate large amounts of vehicles. A disadvantage is that exact vehicle positions are of no importance within this model, but they are very important for transitioning vehicles between the two levels of the simulation. Thus the FASTLANE model has to be extended to approximate the spatial positions of vehicles.

\section{Acknowledgments}

The FIVIS project was funded by the BMBF-FH3 Program "Angewandte Forschung an Hochschulen im Verbund mit der Wirtschaft", funding for the FIVIS 2 project was provided by the DGUV (FP 307), and the AVeSi project is being funded by the FHprofUnt Program of the BMBF (17028X11).

\section{References}

[1] Bungartz, H.-J., Zimmer, S., Buchholz, M., Pflüger, D. Modellbildung und Simulation, Springer, 2009.

[2] Cetin, N., Burri, A., Nagel, K. A large-scale agent-based traffic microsimulation based on queue model. In Proc. of Swiss Transport Research Conference (Monte Verita, 2003).

[3] Gawron, C. An interactive algorithm to determine the dynamic user equilibrium in a traffic simulation model. In International Journal of Modern Physics C 9, 3 (1998) 
[4] Gawron, C. Simulation based traffic assignment - Computing user equilibria in large street networks, PhD thesis (Cologne 1999).

[5] Grether, D., Neumann, A., Nagel, K. Simulation of urban traffic control: A queue model approach. Submitted to The 1st International Workshop on Agent-Based Mobility, Traffic and Transportation Models, Methodologies and Applications (2012).

[6] Herpers, R., et al. Multiple Sensorial Media Advances and Applications: New Developments in MulSeMedia, IGI Global, 2011, ch. Multimedia Sensory Cue Processing in the FIVIS Simulation Environment, pp. 217-233.

[7] Herpers, R., et al. FIVIS - A Bicycle Simulation System, In World Congress on Medical Physics and Biomedical Engineering (WC 2009), IFMBE Proc. Vol. 25/4 (Berlin, 2009), Springer, pp. $2132-2135$.

[8] Lighthill, M. J., Whitham, G. B. On kinematic waves: II. A theory of traffic on long crowded roads. In Proceedings of the Royal Society A (London, 1955), Vol. 229, No. 1178 , pp. $317-345$.

[9] Rosswog, S., Wagner, P. Towards a macroscopic modeling of the complexity in traffic flow, In Phys. Rev. E Stat. Nonlin. Soft Matter Phys 65, 3 Pt 2A (February 2002).

[10] Seele, S., Herpers, R., Bauckhage, C. Cognitive agents for microscopic traffic simulations for virtual environments. To appear in Entertainment Computing - ICEC 2012.

[11] Simon, P., Esser, J., Nagel, K. Simple queueing model applied to the city of Portland. In International Journal of Modern Physics C 10, 5 (1999), 941 - 960.

[12] Treiber, M., Hennecke, A., Helbing, D. Congested traffic states in empirical observations and microscopic simulations. In Physical Review E 62, 2 (August 2000), $1805-1824$.

[13] Treiber, M., Kesting, A. Verkehrsdynamik und -simulation, Springer, 2009. 


\title{
Current work on the optimization of flight personnel schedules within project DOGS
}

\author{
Patrick Kuckertz \\ kuckertz@informatik.uni-koeln.de \\ Department of Computer Science, University of Cologne \\ Institute of Communications Engineering, Cologne University of Applied Sciences
}

\section{Introduction}

The construction of a flight plan is a very challenging task whose complexity depends on the number of offered connections and the length of the planning horizon. In order to reduce complexity the task is usually divided into smaller interconnected planning stages concerning flight schedule design, fleet assignment, aircraft routing and personnel scheduling.

Project DOGS, introduced in [4], is concerned with the Crew Pairing Problem (CPP), a combinatorial optimization problem within personnel scheduling. On the one hand the CPP aims at the valid compilation of flight services (jobs) to so called pairings, and on the other hand combining these pairings to optimal personnel schedules covering all jobs of a flight plan. While the CPP is mostly discussed in conjunction with personnel cost reduction, project DOGS focuses on the development of tools and methodologies to build robust personnel schedules. Neither the term robustness nor the ways of its measurement however are yet conclusively defined (see e.g. [3,5]). Common methods of pursuing robustness are the allocation of buffer times and the avoidance of aircraft changes within pairings. These methods reduce occurrence probabilities and delay propagation of disruptions and will be implemented in our project through penalty costs.

Our definition of the Job Pairing Problem (JPP) allows us to follow a more detailed approach during optimization by regarding single jobs and crew members instead of whole flightlegs and crews (see [4]). It enables us to additionally consider standby jobs at airports and to account for job requirements and personnel qualifications.

In the future the results of the optimization process are to be verified by an event based simulation, analyzing the dynamic properties of personnel schedules. The simulation will also provide us with information about the most suitable deployment of standby personnel.

\section{Optimization}

The mathematical model developed to solve the CPP and hence the JPP is based on the Set Partitioning Problem (see [1]). It implements specifications and regulations coming from labor legislation, union agreements and operational procedures. The model's solution space consists of all valid pairing combinations covering all jobs to be executed within a schedule. In this space the objective function searches for the solution with minimal costs. To not discard optimality and to allow finding the optimum regardless the starting point of the search the model's neighborhood relations indirectly connect all solutions with one another. Two transition functions implement this neighborhood: Join 


\begin{tabular}{|c|c|c|c|c|c|}
\hline \begin{tabular}{|c|c|c|c|}
\hline Data \\
Instances
\end{tabular} & \# Airports & \# Flightlegs & \# Flighthours & \# Days & Network Type \\
\hline T1 & 7 & 14 & 13,5 & 1 & HSS Simple \\
\hline T2 & 8 & 22 & 27,5 & 2 & HSS Simple \\
\hline T3 & 12 & 30 & 48 & 3 & HSS Extended \\
\hline 4P_38L & 4 & 38 & 41 & 1 & HSS Extended \\
\hline 4P_38L_5D & 4 & 190 & 205 & 5 & HSS Extended \\
\hline T4 & 16 & 216 & 1087 & 8 & Network \\
\hline T5 & 18 & 219 & 769 & 7 & Network \\
\hline T5_3W & 18 & 657 & 2307 & 21 & Network \\
\hline
\end{tabular}

Table 1: Data of simplified flight plans

and Split (following [2]). Join combines two pairings to one new pairing, leading from a solution with $n$ pairings to a neighbor solution with $n-1$ pairings. Split does the opposite by dividing the flightlegs of a pairing into two new pairings. Both functions only return valid solutions avoiding the inclusion of invalid neighbors. The size of the neighborhood is important for the performance of the optimization process an is still subject to analysis.

To get a first impression of the functioning and resolvability of the CPP a set of solution heuristics were implemented, applied to simplified flight plans and compared from an application-oriented point of view. The set of heuristics comprised two versions of a hill climber differing in the extend of their neighborhood search, a simulated annealing algorithm and a full enumeration algorithm. To provide the solver with valid initial solutions the procedures trivial solution and linear chainer were implemented. While the trivial solution decomposes a flight plan by creating pairings each containing only one flightleg, the linear chainer assembles pairings of flightlegs with minimal in between times. The simplified flight plans differ in the numbers of airports and flightlegs operated, in the numbers of flight hours and days of operation and in their underlying network structure (see table 1).

Table 2 lists the results of the application of the solver on the flight plans, showing computing times and resulting costs. The results of the stochastic simulated annealing procedure are average values derived from ten optimization runs per flight plan.

\begin{tabular}{|c|c|c|c|c|c|c|c|c|c|c|c|}
\hline \multicolumn{4}{|c|}{ Test Instances } & \multirow{2}{*}{$\mathrm{T} 1$} & \multirow{2}{*}{$\mathrm{T} 2$} & \multirow{2}{*}{ T3 } & \multirow{2}{*}{ 4P_38L } & \multirow{2}{*}{ 4P_38L_5D } & \multirow{2}{*}{ T4 } & \multirow{2}{*}{ TS } & \multirow{2}{*}{ T5_3W } \\
\hline Name & Type & Init. Solution & Unit & & & & & & & & \\
\hline \multirow{2}{*}{\multicolumn{2}{|c|}{ Full Enumeration }} & \multirow{2}{*}{ - } & Cmp. Time [s] & $>3600$ & $>3600$ & \multirow{2}{*}{ - } & \multirow{2}{*}{ - } & \multirow{2}{*}{ - } & \multirow{2}{*}{ - } & \multirow{2}{*}{ - } & \multirow{2}{*}{ - } \\
\hline & & & Cost $[€]$ & 9.200 & 22.550 & & & & & & \\
\hline \multirow{8}{*}{ Hillclimber } & \multirow{4}{*}{ Simple } & \multirow{2}{*}{ Triv. Solution } & Cmp. Time [s] & 0,26 & 0,26 & 0,28 & 0,29 & 0,83 & 1,3 & 0,48 & 9,7 \\
\hline & & & Cost [€] & 9.200 & 22.400 & 36.300 & 40.800 & 176.700 & 518.000 & 518.100 & 1.522 .200 \\
\hline & & \multirow{2}{*}{ Lin. Chainer } & Cmp. Time [s] & 0,26 & 0,28 & 0,28 & 0,3 & 0,9 & 0,55 & 0,7 & 37 \\
\hline & & & Cost [€] & 11.450 & 18.400 & 35.250 & 40.450 & 201.450 & 601.450 & 777.200 & 4.138 .700 \\
\hline & \multirow{4}{*}{$\begin{array}{l}\text { Steepest } \\
\text { Descent }\end{array}$} & \multirow{2}{*}{ Triv. Solution } & Cmp. Time [s] & 0,28 & 0,29 & 0,31 & 0,36 & 0,9 & 8,4 & 8,6 & 356 \\
\hline & & & Cost $[\epsilon]$ & 9.200 & 18.400 & 33.950 & 33.000 & 153.000 & 517.800 & 483.450 & 1.434 .500 \\
\hline & & \multirow{2}{*}{ Lin. Chainer } & Cmp. Time [s] & 0,27 & 0,28 & 0,3 & 0,31 & 3,1 & 0,75 & 2 & 196 \\
\hline & & & Cost [€] & 11.450 & 18.400 & 35.250 & 39.050 & 200.350 & 590.800 & 774.200 & 4.126 .100 \\
\hline \multirow{4}{*}{\multicolumn{2}{|c|}{ Simulated Annealing }} & \multirow{2}{*}{ Triv. Solution } & Cmp. Time [s] & 0,025 & 0,04 & 0,3 & 2,8 & 187 & 239 & 112 & 3026 \\
\hline & & & Cost $[€]$ & 9.200 & 18.400 & 31.950 & 29.900 & 163.800 & 504.600 & 477.600 & 1.442 .900 \\
\hline & & \multirow{2}{*}{ Lin. Chainer } & Cmp. Time [s] & 0,03 & 0,025 & 0,8 & 9 & 178 & 157 & 290 & 3740 \\
\hline & & & $\operatorname{Cost}[€]$ & 9.200 & 18.400 & 31.950 & 29.550 & 162.600 & 507.950 & 473.100 & 1.491 .700 \\
\hline
\end{tabular}

Table 2: Application results 
Results show that the full enumeration procedure is not applicable for other than very small flight plans because of its high computing times. For instances T1 and T2 the procedure was aborted after on hour and the best results found were noted. The simple hill climber produced its best results starting from a trivial solution. This is explained by the fact that the hill climber procedure does not use the split operation which always leads to increased costs and therefore has more options during optimization starting from a decomposed initial solution. The steepest descent hill climber leads to lower costs and higher computing times than the simple hill climber, since more neighbors are investigated at each step. Simulated Annealing produces nearly similar results independent of the initial solution. This is typical for this approach, since in the beginning of the procedure there is a high probability to accept worse solutions.

\section{Future work and unresolved issues}

The upcoming tasks within project DOGS address the optimization of real size flight plans and the enhancement of computing times. In this regard the implemented data structures have to be reworked and the transition functions have to be tested for resulting neighborhood sizes. When these steps are finished we can attend to the implementation of an event based simulation for validating results obtained during optimization.

In order to comply with these tasks a few topics have to be further investigated. For example it is not yet clear how the decomposition of flight legs into multiple tasks within the JPP will affect the resolvability of the personnel scheduling. Further it is still not conclusively decided which elements of other stages of an airline's operations planning process have to be included into the simulation and to what extend the optimization and simulation are to interact.

\section{Acknowledgements}

This work was supported by Rhein Energie Stiftung Jugend Beruf Wissenschaft under grant number W-10-2-002.

\section{References}

[1] Borndörfer, Ralf; Schelten, Uwe; Schlechte, Thomas; Weider, Steffen: A Column Generation Approach to Airline Crew Scheduling. Operations Research Proceedings 2005, pp. 343-348. Springer, 2006.

[2] Emden-Weinert, Thomas; Proksch, Mark: Best Practice Simulated Annealing for the Airline Crew Scheduling Problem. Journal of Heuristics, Vol. 5, pp. 419-436, 1999.

[3] Gopalakrishnan, Balaji; Johnson, Ellis L.: Airline Crew Scheduling: State-of-theArt. Annals of Operations Research, Vol. 140, pp. 305-337. Springer, 2006.

[4] Kuckertz, Patrick; Ullrich, Oliver; Randerath, Hubert: A simulation based approach on robust airline job pairing. Simulation Notes Europe (SNE), Vol. 22, 2012. 
[5] Lavoie, Sylvie; Minoux, Michel; Odier, Edouard: A multi-objective genetic algorithm for robust flight scheduling using simulation. European Journal of Operational Research 177, pp. 1948-1968. Elsevier 2007. 



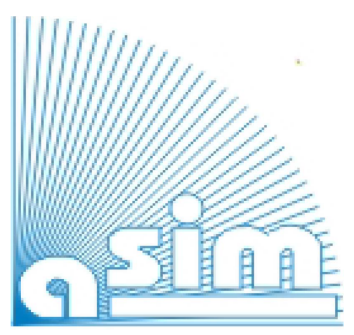

Fran ARGESIM 